\title{
La política de la despolitización. Un análisis de la construcción del relato PRO
}

\author{
MAURICIO SCHUTTENBERG*
}

Artículo recibido: 10 de noviembre de 2016

Artículo aceptado: 3 de marzo de 2017

Doi: http://dx.doi.org/10.12804/revistas.urosario.edu.co/desafios/a.5259

Para citar este artículo: Schuttenberg, M. (2017). La política de la despolitización. Un análisis de la construcción del relato PRO. Desafíos, 29(2), 277-311. doi: http://dx.doi.org/10.12804/ revistas.urosario.edu.co/desafios/a.5259

\section{Resumen}

Recientemente la alianza Cambiemos logró acceder al gobierno argentino por elecciones e incluso ganar un histórico bastión del peronismo como lo era la provincia de Buenos Aires. Este triunfo del PRO rompe con la bistórica dificultad de la derecha de lograr acceder al poder por medios electorales. Esta situación, inesperada para un sector amplio de las ciencias sociales, reabre indudablemente el debate en torno a los alcances y a la naturaleza del proceso politico en ciernes. El articulo propone un análisis del discurso politico para mostrar la conformación de un relato que tiende a ocultar la dimensión conflictiva de la politica y reemplazarla por una concepción consensualista a la vez que se construye desde una mirada deshistorizadora de nuestro pasado como elemento nodal del relato.

Palabras clave: derechas, Argentina, politica, identidades, Cambiemos

* Doctor en Ciencias Sociales (Facultad Latinoamericana de Ciencias Sociales, Argentina). Magíster en Ciencia Política (Universidad Nacional de La Plata). Investigador Asistente de CONICET en IdIHCS-UNLP. Profesor adjunto de Problemas de Historia Argentina en la Universidad Nacional Arturo Jauretche y de Historia de las Ideas y los Procesos Políticos en la Facultad de Periodismo y Comunicación Social de la Universidad Nacional de La Plata. Correo electrónico: mauricioschuttenberg@gmail.com. ORCID http://orcid. org/0000-0002-5268-1712 


\title{
The Politics of Depolitization. An Analysis of the Construction of the PRO Alliance in Argentina
}

\begin{abstract}
Abtract
The political alliance Cambiemos (PRO) has recently become part of the Argentinean national government by winning, among others, in historical strongholds of the Peronist movement such as the province of Buenos Aires. The triumph of PRO breaks with the historical difficulty of the right to gain access to power by electoral means. This situation, which was unexpected by a large segment of the social sciences, undoubtedly reopens the debate about the scope and nature of the political process in the making. The article proposes an analysis of political discourse in order to demonstrate the formation of a discourse that tends to bide the conflictive dimension of politics and replaces it with a consensualist conception while being based on an abistorical perspective on the past as an essential element of the story.
\end{abstract}

Keywords: Political right, Argentina, politics, identities, Cambiemos

\section{A política da despolitização. Uma análise da construção do relato PRO}

\begin{abstract}
Resumo
Recentemente a aliança Cambiemos conseguiu aceder ao governo argentino por eleições e inclusive ganhar um histórico do peronismo como o era a provincia de Buenos Aires. Este triunfo do PRO rompe com a bistórica dificuldade da direita de conseguir aceder ao poder por meios eleitorais. Esta situação que resultou inesperada por um setor amplo das ciências sociais reabre indubitavelmente o debate em torno aos alcances e natureza do processo político em amadurecimento. O artigo propõe uma análise política para mostrar a conformação de um relato que tende a ocultar a dimensão conflitiva da politica e substitui-la por uma conceição de consensualidade que ao mesmo tempo se constrói desde um olhar des-historizada do nosso passado como elemento nodal do relato.
\end{abstract}

Palavras-chave: direitas, Argentina, politica, identidades, Cambiemos 


\section{Introducción}

A lo largo de por lo menos los últimos dos siglos, la teoría política tendió a dividir el espacio político en dos grandes bloques: derecha e izquierda. Estos espacios se identificaron con nociones de orden o progreso; libertad versus igualdad; modernización o tradición. Estos ejes sobre los cuales estos bloques reconfiguraron sus posiciones sirvieron como elementos de análisis para la teoría política y la historia de las ideas. Izquierda y derecha se transformaron entonces en dos formas de dar cuenta de dos espacios ineludibles en el estudio de las dinámicas políticas. No solo las ciencias sociales tomaron estas definiciones sino también los propios actores se fueron autoadscribiendo en vinculación a esos espacios.

Recientemente la alianza Cambiemos ${ }^{1}$ logró acceder al gobierno argentino por la vía electoral e incluso ganar un histórico bastión del peronismo como lo era la provincia de Buenos Aires. Este triunfo del PRO rompe con la histórica dificultad de la derecha de lograr acceder al poder por medios electorales. Desde la recuperación de la democracia en 1983, diferentes experiencias de la derecha intentaron llegar al gobierno y ninguna tuvo éxito como partido "puro". Esta situación reabrió el debate en las ciencias sociales en torno a los alcances y naturaleza de un proceso político en ciernes. Uno de esos desafíos es pensar la política de un discurso negador de tal dicotomía política, es decir la inexistencia o la inconveniencia de seguir hablando de izquierda o derecha, a la vez que subordina la política y reconstruye una historia.

En este trabajo interesa explorar una dimensión poco estudiada del discurso de la reciente alianza gobernante. En el último tramo de la campaña presidencial de 2015, y en los años anteriores también,

\footnotetext{
1 Cambiemos es una coalición política de Argentina conformada durante el trascurso del año 2015, y surge del acuerdo entre Elisa Carrió (de la Coalición Cívica ARI), Mauricio Macri (del PRO) y Ernesto Sanz (de la Unión Cívica Radical).Son parte de la alianza también el Partido Fe, el Partido Demócrata Progresista, el Partido Conservador Popular y el Partido del Diálogo, aunque estos últimos son fuerzas de menor presencia y peso político.
} 
hubo algunos abordajes de los discursos de derecha y de su crítica u objeciones al modelo "nacional y popular". Lo que resulta central para el análisis es la necesidad, una vez en el gobierno, de construir un relato que dé sentido al accionar político de la nueva fuerza. Es decir, el trabajo se concentrará en tratar de profundizar el análisis en lo que denominaremos el relato del gobierno y su dimensión ideológica.

En los últimos años, la etapa de la Argentina posneoliberal tuvo una gran cobertura desde las ciencias sociales. Algunos enfoques debaten sobre el carácter y las particularidades del kirchnerismo, otros sobre la articulación con el campo popular, etc. Ahora bien, el denominado giro a la izquierda continental (Muñóz, 2011) parece estar en jaque por algunos sucesos recientes ocurridos en Brasil, Venezuela e incluso por el triunfo del $\mathrm{NO}$ a la reelección de Evo Morales en Bolivia. El tema central que nos ocupa es el triunfo en las elecciones en segunda vuelta del PRO, partido que articula un discurso de derecha en Argentina.

Es por ello que es necesario profundizar en el conocimiento de lo que es una nueva etapa política en nuestra historia. La propuesta es adentrarnos en lo que denominamos relato, es decir el discurso del actual gobierno y su articulación en busca de legitimidad hegemónica. En definitiva, nos proponemos pensar el PRO como una identidad que fue construyendo una cadena de equivalencias que consolidó una frontera antagónica con el kirchnerismo y, que en un segundo momento, comienza a poner en escena su identidad y su relato.En este trabajo proponemos un avance en el análisis de la alianza gobernante como una fuerza política que deja su primer núcleo ideológico sustentado en el antikirchnerismo y comienza a plantear un proyecto ideológico propio.

La hipótesis que guía el trabajo es que uno de los ejes sustanciales en el nuevo relato es la visión de la política. Esta se caracteriza, como se intentará demostrar, por la conformación de un discurso que tiende a ocultar la dimensión conflictiva de la política y reemplazarla por una concepción consensualista a la vez que se construye desde una mirada deshistorizadora de nuestro pasado. 


\section{Hegemonía, relato y política. Algunas precisiones conceptuales y metodológicas}

El artículo se basa en un análisis político del discurso desde una mirada teórica metodológica posfundacional. Esta perspectiva, que presentaremos a continuación, se construyó a partir de diversos autores y algunas categorías centrales de esta línea analítica. Conceptos como identidad, hegemonía, relato, significantes vacíos, fronteras identitarias, cadenas de equivalencias y articulación política fueron los que resultaron particularmente sensibles para abordar las fuentes y dar cuenta de los objetivos del trabajo.

Introducirnos en el análisis del discurso implica pensar las formas en las cuales las identidades buscan construir consensos en torno a sus ideales, esto es, la disputa por la hegemonía que supone la significación de la totalidad. Una totalidad que aspira a partir de un particular que, sin dejar de serlo, comienza a vaciarse de contenido, inscribiendo y articulando otras particularidades $\left(\right.$ Laclau, 2005) ${ }^{2}$. Estas particularidades se construyen como cadenas de equivalencias que articulan distintas particularidades. En este sentido, interesa analizar cómo se intenta consolidar una nueva formación ideológica y disputar la hegemonía (Schuttenberg, 2014).
Aboy Carlés (2001, 2005 y 2011), siguiendo a Laclau (2005), se- ñala que, al definir un enemigo común, una formación política debilita y cuestiona sus diferencias internas y se constituye como totalidad a través de lo que Laclau y Mouffe (2004) denominaron una lógica de equivalencia (Schuttenberg, 2008b, p. 187).

Es precisamente esa lógica la que impide que toda identidad social sea plenamente constituida, en la medida en que la definición de un exterior implica su debilitamiento en tanto diferencias internas (Schuttenberg, 2008). Para Laclau ${ }^{3}$, la constitución de equivalencias,

\footnotetext{
2 La cuestión de la hegemonía desde la perspectiva de Laclau puede ampliarse en Howarth, (2008) y en Barros (2006).

3 De la extensa obra de Laclau nos centramos en (Laclau, 1985a; 1985b; 1994; 1998; 2000;2002 y 2005).
} 
el cierre de un espacio de diferencias frente a un exterior tiene siempre la forma de una operación hegemónica: un particular que se convierte en universal aglutinando un espacio político frente a una alteridad, lo que implica la no realización plena de la identidad de todas las fuerzas equivalentes dentro del espacio así constituido (Aboy Carlés, 2001).

Desde esta perspectiva toda identidad política se constituye en referencia a un sistema temporal en el que la interpretación del pasado y la construcción del futuro deseado se conjugan para dotar de sentido a la acción presente. Para una sociología de las identidades políticas la identidad de historia y política queda de manifiesto en el hecho de que el pasado, siempre abierto, puede ser reconstruido en función de un presente y un porvenir. Los hechos no hablan por sí mismos, son significantes flotantes que podrán siempre ser rearticulados conforme al devenir de una identidad (Aboy Carlés, 2001, p. 46).

Las identidades se constituyen en la conformación de un relato que busca su trascendencia en un pasado y un futuro acorde a sus concepciones. Para este abordaje es fundamental pensar en cómo los mitos (Barthes, 1999) pueden suturar la dislocación a través de la conformación de un nuevo espacio de significación. Interesa pensar cómo cada fuerza política intenta refundar el espacio político a través de un mito inaugural donde pone en juego su identidad.

Coincidimos con Barthes (1999) en señalar que el relato está presente en todos los tiempos, en todas las sociedades y en todas las ideologías. No es posible construir una identidad sin relatos que le den sentido. Esto apunta justamente a uno de los objetivos centrales de nuestro aporte: tratar de analizar el discurso de la alianza gobernante en tanto relato que niega su propia condición. La negación de la politicidad de su propio discurso es justamente una de las formas de construir una identidad.

Para ello es central la noción de identidad puesto que a partir de allí podríamos recortar dos dimensiones significativas: la representación de la sociedad y el programa político (Eccleshall, 1993). Según este 
autor, las identidades ofrecen una visión de la sociedad inteligible y para ello acentúan y contrastan distintos aspectos del mundo social a fin de ilustrar cómo actúa la realidad en todo su conjunto y también cómo se debería organizar desde el enfoque propuesto. A partir de este desarrollo se transmite un programa de acción en busca de acercar el ideal y la realidad planteados que otorga una perspectiva coherente (Schuttenberg, 2014).

A la hora de proponer el análisis de los discursos debemos definir esta noción. Van Dijk (1989) plantea que el discurso se interpreta como un evento comunicativo completo en una situación social. Lo que distingue el análisis de discurso de la gramática de la oración es que el análisis de discurso, en la práctica, se concentra específicamente en los fenómenos detrás de la oración (Van Dijk, 1989; Maingueneau, 1984).

Otra cuestión fundamental es que el discurso político está signado por su carácter polémico e incorpora el conflicto como su componente enunciativo primordial (Pérez, 2004, p. 184). En esta misma línea, para Verón (1987) el campo discursivo de lo político implica enfrentamiento, relación con un enemigo, lucha entre enunciadores, determinando una dimensión polémica del discurso político y la construcción de un adversario.

La política comporta necesariamente cierta dosis de polémica dado que es el terreno en el que se dirimen las diferencias, controversias y disputas inherentes al mundo de lo público y lo común. Abordar las formas lingüísticas que esas disputas asumen en el discurso político supone adentrarse en el vasto campo del discurso polémico, ámbito en el que se produce la confrontación y la puesta en escena de voces o puntos de vista diversos, con el consiguiente despliegue de los antagonismos y conflictos políticos, que son también - y sobre todo- semánticos, enunciativos y argumentativos. Estos se constituyen en "marcos" discursivos fundados en una serie de principios que sustentan los posicionamientos ideológicos (Montero, 2011). En este aspecto, retomamos el concepto de lo político en los términos de Carl Schmitt (1999) que lo caracteriza como la distinción "amigo- 
enemigo". Los gobiernos neoliberales construyen un discurso político que busca borrar la politicidad de la propia enunciación.

Interesa abordar estos discursos desde la óptica de la argumentación. El análisis ideológico es diferente del análisis de la argumentación en el discurso (Amossy, 2000). Se distinguen en la medida en que el primero pretende esencialmente denunciar una visión de mundo alienada, en tanto que el análisis argumentativo, si es crítico, no se asimila por ello a una desmitificación sino que busca comprender cómo los elementos construyen una operación de persuasión.

En el mismo sentido, Gruner (2010) señala que la interpretación no está destinada a disolver "falsas apariencias", sino a mostrar de qué manera esas "apariencias" pueden expresar una cierta verdad que debe ser construida por la interpretación. Esas verdades son, para el autor, espacios de inteligibilidaddesde el cual todo el "mapa" de la cultura se recompone. El artículo propone entonces un análisis de la ideología pensada como espacio de inteligibilidad para comprender a partir de allí la acción política (Verón y Sigal, 2004).

En términos metodológicos, el artículo se fundamenta en un análisis político del discurso sostenido en las categorías desarrolladas en el apartado a partir de un corpus empírico basado en declaraciones y notas de opinión de intelectuales vinculados a la alianza gobernante en los medios de mayor circulación, artículos, entrevistas a referentes, notas de opinión, documentos de coyuntura y publicaciones partidarias. El criterio de recorte de los textos apunta a dar cuenta del objetivo central del trabajo de sumergirse en el universo ideológico de Cambiemos por lo que se incluyeron artículos de opinión de figuras vinculadas a este espacio político como "intelectuales" en el sentido en que aportan a la conformación de un diagnóstico, a la construcción de interpretaciones de coyuntura y de planes de acción.

Para la conformación del corpus se efectuó un seguimiento exhaustivo de los posicionamientos de los referentes del gobierno así como de algunos de sus principales intelectuales en los diarios de circulación nacional más importantes. Se realizó una búsqueda periódica desde 
2007 en esos medios de tirada nacional (Clarín, La Nación, Página 12, Revista Noticias y Perfil) para recuperar los posicionamientos ideológicos. Asimismo, se tomaron documentos que la alianza Cambiemos publicó en la coyuntura preelectoral de 2015 y una vez en el gobierno. Toda la búsqueda apuntó a responder a la pregunta acerca de cómo se construye el nuevo relato ideológico. El artículo muestra entonces extractos significativos de ese corpus para sostener la hipótesis central que guía el trabajo, a saber, es la conformación de un nuevo relato en torno a la política.

\section{Breve genealogía de la derecha no peronista}

A la hora de pensar el campo de la derecha ${ }^{4}$ debemos tener en cuenta otro eje divisorio sustantivo en la política argentina que es el de peronismo y antiperonismo (Retamozo y Schuttenberg, 2016). La insuficiencia del clivaje ${ }^{5}$ izquierda-derecha para la comprensión de la dinámica política argentina ha sido frecuentemente enunciada. La irrupción del peronismo y los intentos de conceptualizarlo evocaron la necesidad de otros clivajes: civilización o barbarie, autoritarismo o democracia, nacional o colonial.

Ha sido, sin dudas, Pierre Ostiguy (1997, 1999, 2005, 2013a, 2013b) el que más sistemáticamente ha trabajado para teorizar esta intuición sobre el "doble espectro político argentino" o "dos clivajes de la política argentina” (Alessandro, 2009). Ostiguy distingue lo alto/ bajo en términos de "estilos" que se cristalizan en los modos de intervención política y escenificación pública a partir de una serie de prácticas de producción de sentido (discursos, actos, movilizaciones, spots publicitarios, etc). Este autor plantea que la fractura izquierdaderecha se encuentra entrecruzada en la Argentina por un clivaje aún más poderoso, de características socioculturales que se vincula con "maneras, modales, modos de hablar y vestir, gustos exhibidos en

\footnotetext{
4 Para una visión clásica ver Bobbio (1995) y para el caso argentino se puede consultar Mc Gee Deutsch (2005) y Tato (2013).

5 La idea de clivaje la desarrollaron Lipset y Rokkan (1967).
} 
público" separando estilos y apelaciones más populares y llanas de aquellas más refinadas, formales o intelectuales (Retamozo y Schuttenberg, 2016).

Desde el retorno a la democracia en 1983 el antecedente con mayor impacto electoral e identitario fue la Unión del Centro Democrático (Ucede), organización que llegó a obtener casi dos millones de votos en la figura del ingeniero Álvaro Alsogaray en las elecciones de 1989. No obstante, en otra de las paradojas de la historia, este partido de tradición liberal y fuertemente antiperonista fue absorbido por el Partido Justicialista durante los años de apogeo del neoliberalismo de la mano de Menem.

Heredero de esa tradición liberal conservadora, el exministro de economía de Menem, Domingo Cavallo, fundó en 1999 el partido Acción por la República (Vommaro y Morresi, 2014). Luego de una fallida participación en los comicios de 2001 se plegó tras la candidatura de Menem en 2003. En ese mismo espacio ideológico, y luego de abandonar la Unión Cívica Radical en 2002, López Murphy fundó el partido Recrear para el Crecimiento (Recrear). En 2003 se presentó a las elecciones como candidato a presidente de la Nación, obteniendo el tercer lugar con el $18 \%$ de los votos. Recrear para el Crecimiento proponía una profundización de las políticas de los noventa interpretando que en esos años la Argentina se habría distanciado del liberalismo ${ }^{6}$ (Schuttenberg, 2014). Estas vertientes las podríamos situar en el cuadrante propuesto, arriba y a la derecha (Schuttenberg y Retamozo, 2016).

Esta derecha "alta", que obtuvo presencia electoral en 2003 en la figura de López Murphy, tendió a retroceder al ser reinscrita por el discurso kirchnerista que se autoconstituyó como antagonista de estas figuras como representantes del neoliberalismo. El triunfo de Cristina Fernández en las elecciones para presidente de 2007 trajo consigo la fragmentación de la oposición. La fuerza que organizó

\footnotetext{
6 Puede consultarse: López Murphy: “Lo que hizo Menem no fue liberalismo” La Nación, domingo 2 de marzo de 2003.
} 
coyunturalmente este espacio emanó de la figura de Elisa Carrió, cuya construcción política se basó en un discurso de denuncia a las "mafias" del Partido Justicialista y en la reivindicación de las formas republicanas de gobierno.

El discurso opositor se centró más en la lucha contra el peronismo como una fuerza en los márgenes sociales reeditando la antinomia civilización o barbarie y menos en las premisas del Estado mínimo neoliberal de la derecha más extrema (Schuttenberg, 2014). Estas fuerzas se fueron desplazando hacia el centro derecha a partir del avance del gobierno kirchnerista en distintas iniciativas de recuperación de las capacidades políticas y de la soberanía política del Estado.

Entre tanto en 2007 se consolida otro polo de la derecha con el triunfo de Mauricio Macri en las elecciones para la Jefatura de Gobierno de la Ciudad de Buenos Aires. En ese contexto, el PRO articula un discurso en abierta oposición al gobierno nacional y de alineamiento antagonista en cada uno de los conflictos, especialmente luego de la resolución 125 que derivó en un conflicto con los empresarios del sector agrario y la "Ley de Medios". Allí, este partido se instala con un discurso crítico de la intervención estatal y de la primacía de la política por sobre la economía (Schuttenberg y Fontana, 2013).

En 2011, Macri obtiene su reelección. A partir de ese momento el desafío del PRO fue replicar el crecimiento y gravitación a nivel nacional que supo obtener en el distrito de Capital Federal. En esa estrategia podemos observar un abandono de la reposición de sentidos más típicamente conservadores por un enfoque deliberada e ideológicamente desideologizado. Un ejemplo sería el impulso que Vommaro, Morresi y Belloti (2014) señalan: a diferencia de otros partidos de centro derecha argentinos, el PRO no se presenta como un partido doctrinario y fundamentalmente antiperonista, sino que busca ampliar sus bases de apoyo tras un discurso más amplio. 


\section{El giro discursivo en la presidencia de Cristina Fernández}

En la segunda presidencia de Cristina Fernández (2011-215), el PRO continuó estructurando un discurso articulado sobre los significantes como "inseguridad", "caja", "política populista"; estos fueron los puntos nodales en torno a los cuales el partido intentó construir una frontera con lo que se construía como enemigo, esto es el populismo. Desde este discurso fuertemente confrontativo fue virando a una posición más consensualista con el avance de la presidencia de Cristina. De esta forma, el PRO se posicionó como la expresión de una tercera vía en discusión con "la vieja política del siglo XX"

En ese marco, el PRO se construye como un heredero de 2001, como una fuerza absolutamente escindida de las disputas, legados y tradiciones anteriores dando lugar a una memoria de corto alcance en la conformación de su identidad. El 2001 se constituye como mito fundante de lo que identifican un nuevo acercamiento a la política.

El año 2001 marcó a fuego a la Argentina. En aquel diciembre terminaba algo más que un gobierno y una política económica. Los expertos lo llamaron "crisis de representación”. En efecto, la sociedad civil percibió que sus representantes se habían alejado de quienes los habían legitimado una y otra vez con el voto. La realidad que se había intentado ocultar salía a la luz y las opciones políticas clásicas dejaron de dar respuestas. Derecha e izquierda, capitalismo y socialismo, peronismo y radicalismo, populismo y neoliberalismo se habían convertido en falsas opciones. Los planteos de unos y de otros se habían convertido en algo ajeno. Sus reglas, sus formas, su vocabulario y sus reivindicaciones habían perdido su contacto con la realidad que se vivía ${ }^{8}$.

\footnotetext{
Devoto, M. (2014). La vía PRO. Documento disponible en http:/ / mauriciodevoto.com. ar/tag/via-pro/

8 Devoto, M. (2014). La vía PRO. Recuperado el 4 de mayo de http://mauriciodevoto. com.ar/tag/via-pro
} 
En ese relato histórico, la crisis de 2001 es un parteaguas, aunque diferente de los relatos nacional populares que interpretaban dicha crisis como el fin del proyecto neoliberal. El PRO construye un discurso en el cual la significación de 2001 está vinculada más al fracaso de una forma "antigua" de concebir la política, es la demostración del fracaso de las ideologías del siglo XX.

Este fracaso en la forma de concepción política conforma lo que denominamos la memoria de corto plazo. Allí donde no había tradición ni legados políticos válidos hacia atrás se construye la idea del ciudadano que abandona la comodidad de su hogar y se brinda al espacio público y a la vida política. "Después de años de trabajo, cada uno encerrado en su propio proyecto personal, familiar y profesional, sentíamos que el mayor o menor éxito alcanzado en la vida nos dejaba un sabor amargo. Lo que veíamos alrededor dejaba a la mayoría de los argentinos fuera del sistema, excluidos. Por acción u omisión, nos sentíamos responsables?

Desde esa interpretación surge el vínculo con lo político. En ese contexto, el significante "revolución" cobra el sentido de romper con las viejas tradiciones políticas e imponer otras formas vinculadas a los ideales de bondad, decencia y sensibilidad. En frente, para el PRO, los viejos relatos y consignas como felicidad del pueblo, grandeza de la nación, justicia social, independencia económica, soberanía política, inclusión, república, democracia, igualdad de oportunidades, etc., no eran otra cosa que arengas para obtener poder. Es decir que en esta lectura los partidos políticos tradicionales habrían construido con base en estas divisiones y disputas. "Diseñaron sus relatos, herramientas y burocracia partidaria alrededor de esta lógica. Cuando llegaban al poder trasladaban relato, herramientas y burocracia al aparato estatal ${ }^{10}$ '.

\footnotetext{
9 Devoto, M. (2014). La vía PRO. Recuperado el 4 de mayo de http://mauriciodevoto. com.ar/tag/via-pro

10 Devoto, M. (2014). La vía PRO. Recuperado el 4 de mayo de http://mauriciodevoto. com.ar/tag/via-pro
} 
En 2015, poco tiempo antes de las elecciones, Macri hizo un nuevo giro estatista en su discurso y prometió mantener la Asignación Universal por Hijo. "La Asignación Universal por Hijo no es un regalo, es un derecho. Vamos a trabajar incansablemente para reducir la pobreza, va ser una prioridad del gobierno terminar con la pobreza en la Argentina ${ }^{11} "$. En el mismo tono se mostró favorable a la continuidad de la gestión estatal de Aerolíneas Argentinas, YPF, y otros hitos del gobierno anterior.

Si bien con vistas a las elecciones el PRO se mostró más cercano a mantener políticas inclusivas de los gobiernos kirchneristas, construyó una sólida frontera en relación a ellos. La crispación, la política vinculada a la corrupción, la ineficiencia de un Estado sobredimensionado, las asociaciones internacionales regionales fueron articuladas en una otredad que posicionó al macrismo como fuerza novedosa que vendría a renovar todas las prácticas no deseadas de los anteriores gobiernos.

Este aspecto no es menor puesto que, entendemos, constituyó uno de los puntos fuertes del PRO en la disputa por la hegemonía. La posibilidad de construir un discurso antipopulista pero que, sin embargo, conformó un antagonista claro y delineado fue uno de los aspectos políticos relevantes del último tramo de la campaña.

\section{La política y la normalización}

La alianza Cambiemos, una vez en el poder luego de una ajustada segunda vuelta, articuló un discurso en línea con el avance del neoliberalismo en América Latina. Este relato construye una interpretación de lo social desde el individualismo más extremo. Lo colectivo no existe, solo el sujeto individual. Únicamente el individuo es el protagonista de la historia y el Estado debe limitarse a proteger los derechos de los individuos (Casullo, 2007). Como bien señala este autor, la comunidad

\footnotetext{
11 Ver: "Macri prometió que YPF y Aerolíneas seguirán siendo estatales", La Nación, 19 de julio de 2015, Recuperado el 2 de mayo de 2016: http://www.lanacion.com. ar/1811860-mauricio-macri-prometio-que-ypf-y-aerolineas-seguiran-siendo-estatales
} 
se reduce al individuo y la visión sobre las derechas es fundamental para empezar a delinear el análisis del discurso del PRO. La lectura es que la política, a diferencia de la etapa kirchnerista, no debería considerarse conflictiva sino más bien como consenso sin conflicto (Conno, 2012). En este discurso, la política tiene que ver con el consenso como punto de partida, no como resultado de la lucha política. Pensar en estos términos implica una negación de la política y su reemplazo por una visión que vela los conflictos y la disputa de intereses.

Muchos querrían que lo hubiera, ya sea para pelearse con el relato K o para tener la tranquilidad de pertenecer a una corriente doctrinaria que sirva para explicar toda la vida de acuerdo con un manual. Pero no lo habrá, ni por el concepto relato ni por el concepto M.

Un relato es una simplificación, una explicación, un cuento, y cuando se aplica la categoría relato a la política de un país, lo que resulta es que una parte, un partido, se quiere apropiar de la explicación del todo. Una minoría, con el truco de decir que tiene un "relato nacional", se apropiaría así de la interpretación del conjunto, incluyendo la de la mayoría ajena. Esa vocación de totalidad que tienen los totalitarios (aquellos que van del sóviet al fascismo, pasando por el fin de las ideologías de los años noventa) ni es democrática (en la democracia juegan mayorías y minorías en respeto mutuo) ni es realista.

Tampoco habrá relato $\mathrm{M}$ por el concepto $\mathrm{M}$. No tenemos que inventar la interpretación macrista del universo, del amor, de la vida y del poder. Lo que sí debemos construir entre todos, $\mathrm{M}$ y no M, son los objetivos nacionales de la Argentina y los valores de la convivencia en paz en la Argentina. Ese será el relato de la nueva administración: objetivos nacionales y valores compartidos ${ }^{12}$.

12 Pinedo, F. (2016). "El relato M" en La Nación, 21 de enero de 2016. Recuperado el 2 de mayo de 2016 en http:/ / www.lanacion.com.ar/1863887-el-relato-m 
En la cita anterior se destaca la concepción que el macrismo intenta imprimir sobre la política. En su discurso dice no haber ni desear la conformación de un relato pues este es vinculado a una visión sesgada que tiende a fracturar a las sociedades. Como reverso a esa lectura está la búsqueda de valores y objetivos nacionales que contengan a la sociedad en su conjunto.

Alemán (2016) da cuenta de la operación discursiva en los términos en que "se caracterizan por un discurso insignificante, que se neutraliza a sí mismo y aspira a conseguir el grado cero de la enunciación". Este grado está dado por la negación de lo político como instancia conflictiva, más allá de que en su enunciación la figura del populismo confrontativo es espectral, es decir está fuertemente presente, pero como telón de fondo no explicitado. El "Todos juntos" oculta el antagonismo social, porque habría unos intereses compartidos por el conjunto de la sociedad.

El discurso de la alianza gobernante es el de negar el conflicto y "cerrar la grieta" que los gobiernos kirchneristas habrían abierto. El relato está identificado con una mística falsa que sirve a los intereses de construir una verdad sesgada. El objetivo de la renovación macrista es justamente construir un discurso de "todos" no de una parte. Como bien señala Litvinoff ${ }^{13}$, el PRO construye un vínculo débil con el pasado. Así, se caracteriza como exceso de politización toda interpretación alternativa de los hechos.

Es mentira que los pueblos que no conocen su historia tienden a repetirla. Cabe más concluir lo contrario: los pueblos que se obsesionan con su historia no logran entender ni avanzar, se envician con la muerte y con la nada. La mirada enamorada del pasado es tradicionalista, conservadora. En otro tiempo la tradición pudo ser muy valiosa, las cosas estaban más quietas y era orientador respetar formas establecidas, pero ya no es así. En

13 Litvinoff, D. E. (2016). "Construyendo el sujeto macrista" en Página 12, 31 de agosto de 2016. Recuperado el 30 de abril de 2016 en http:/ / www.pagina12.com.ar/diario/laventana/26-308181-2016-08-31.html 
nuestro acelerado movimiento actual tradición implica retroceso, fracaso, melancolía y cerrazón. El que ancla en lo ideológico adora el pasado y es también impermeable: no le entra el mundo y sus hechos cambiantes, no concibe la legitimidad del paso del tiempo. Lo descarta por incorrecto, quiere descalificar la ley primera de la realidad: el cambio ${ }^{14}$.

La historia es algo a dejar atrás puesto que no solo no nos sirve al futuro sino más bien produce ataduras nostálgicas. El futuro se construye entonces en el discurso como desvinculado de las tradiciones, los procesos anteriores que son más bien obstáculos para la evolución.

La ideología del desarrollo no tiene nada que ver con el pasado, la historia, la crítica o la revancha; la ideología del desarrollo es la positividad, la mirada puesta en lo que se puede, en lo que hay, la voluntad cargada de ganas y de mundo, capaz de aprender, deseosa de generar lo que se quiere vivir. La positividad es lo contrario de nuestra filosofía miserable de tango y de fracaso, considerada de manera patológica como verdad vital profunda. Lo contrario del escepticismo que cultivamos como sabiduría y con el que muchos justifican su falta de compromiso o su mala praxis. El trasfondo filosófico de la positividad, su visión del mundo, dista de negar las dificultades vitales. Entiende que la realidad es y será siempre problemática, que nunca domaremos racionalmente la tumultuosa experiencia humana, pero es también capaz de captar y sentir el gran valor de la vida, la inmensa riqueza que se nos ofrece constantemente, como individuos y como sociedades ${ }^{15}$.

En su lugar se propone el desarrollo. Este solo podría darse según el relato desde el abandono de la política y la historia, estos son pesados lastres que impiden la "positividad", cuestión necesaria para el avance. La historia se construye en articulación con un discurso pesimista y

\footnotetext{
14 Rozitchner, A. (2014). "Positividad, la ideología del desarrollo", La Nación, sábado 11 de octubre de 2014.

15 Rozitchner, A. (2014). "Positividad, la ideología del desarrollo", La Nación, sábado 11 de octubre de 2014.
} 
obstaculizador del cambio. La revolución es entonces romper con ese tradicionalismo.

De esta forma, en la argumentación se da una inversión de los significantes históricamente vinculados al cambio y a la transformación, esta ya no está dada por recuperar las tradiciones emancipatorias latinoamericanas, sino que en su lugar se propone un abandono, un olvido como momento fundante de un nuevo relato.

Hay una política de "lucha" y una política de "crecimiento" o "desarrollo". Cada una de estas ideas encarnan distintas visiones del mundo y distintas posiciones existenciales. Si uno cree que la política es lucha centra su mirada en el enemigo. O en los muchos enemigos que necesita recrear constantemente para alimentar su estructura de sentido. La tarea es enfrentarlos y vencerlos. El día se organiza a partir del odio o del resentimiento, las horas pasan inventando trampas o trucos para debilitar a los detestados. Si uno cree en cambio que la política es una forma de implementar el desarrollo necesario, tiene como tarea organizar situaciones para que los recursos puedan aprovecharse de la mejor manera posible. Busca gestionar para optimizar resultados. Quiere que la mayor parte de las personas disfruten de la mejor situación que el talento organizativo permita alcanzar ${ }^{16}$.

El significante "política" se articula en una cadena de sentido que la concibe con la administración de los recursos que se tienen en un contexto determinado. Esa es la buena política que oculta en el discurso la visión negativa que es la de la confrontación y la del conflicto. Esto último se conecta con la visión que tiende a deshistorizar las trayectorias de los actores sociales y colectivos. Estos son reemplazados por gente o personas que son identificados como sujetos individuales sin intereses colectivos o sectoriales.

16 Rozitchner, A. (2012). "Política de lucha o política de desarrollo", La Nación, viernes 28 de septiembre de 2012. 
En el relato el PRO es el partido de la gente sin trayectoria partidaria que "se mete en política". Allí se construye la figura de los emprendedores, los profesionales y "la gente nueva" que llega a la política sin intereses. Ellos aportan, en esta visión, el saber de sus experticias y no estarían contaminados de la práctica política. Son los ciudadanos sin trayectoria política por lo tanto virtuosos. Ese es uno de los ejes del mito fundante del PRO y su relectura de 2001. En el relato, la crisis habría despertado un deber cívico en una porción de la sociedad que hasta el momento no había participado y es así como se forma el partido. La política se construye como la contracara de la eficiencia y agilidad del sector privado de donde emergen las virtudes ciudadanas. La política es ideología y eso la hace lenta y la aleja de la técnica, de lo que se debería hacer.

Según Hobsbawm (1994), la característica de las derechas es concebir la desigualdad como un dato "natural", consustancial al orden humano. En ese marco, para los sectores conservadores, toda tentativa de modificación social impulsada por grupos subalternos es considerada como un cuestionamiento del orden natural.

Uno de los ejes discursivos del nuevo gobierno es el retorno a la normalidad. ¿Qué significación adquiere esto? La normalidad es de alguna forma cerrar el ciclo kirchnerista. Es decir, las políticas redistributivas del kirchnerismo y la politización de la sociedad son la frontera antagónica de la identidad PRO. La vuelta a la normalidad es volver atrás los avances producidos a partir de 2003, es un giro conservador de larga tradición.

En la búsqueda de ese orden hay una articulación con un pasado no del todo explícito pero presente en el recuerdo de la Argentina de principios de siglo XX donde la tradición liberal era hegemónica. Esta mirada se articula en el discurso con otro eje que identifica al kirchnerismo como el productor de una división binaria del espacio político en la que el gobierno representaba los intereses del pueblo y sus adversarios eran presentados como portavoces de intereses de las grandes corporaciones. 
Cambiemos, en tanto, busca normalizar también al bajar la intensidad del conflicto político. Esta representación implica correr la política de esa lucha de intereses que el kirchnerismo había explicitado en el cuerpo social y pasarlo a un ámbito no conflictivo que tienda a "unir a los argentinos".

El libro Querido Mauricio intenta no ser clásicamente política, por eso lo de "neopolítica". Es decir, busca integrar otras preocupaciones y otros modos de decir para contribuir a una actualización de la idea de política. Nadie sabe muy bien hoy qué es hacer política. En el nuevo escenario la eficacia de un deseo de transformación social requiere modificar pensamientos, actitudes y costumbres. En otra época este texto se hubiera llamado "Carta abierta a Mauricio Macri”, pero olvidate de seguir diciendo "carta abierta" después de la existencia de la conocida agrupación de intelectuales. Creo que el objetivo de tu presidencia debería ser el de producir una mutación psicológica del argentino. Crear las condiciones para que el individuo maduro, íntegro, capaz, responsable, sea una tendencia general y no una excepción. Establecer el marco para que las personalidades sean capaces de otras posiciones existenciales y tiendan a generar crecimiento propio y común más que a victimizarse, paralizarse, y negativizarse (Rozichner, 2015, p. 2).

El objetivo que se plantea en el texto es transformar la actitud hacia lo político. Esto se define en términos de neopolítica, que es dejar atrás la política tradicional para lograr desarrollar las potencialidades individuales. El objetivo de una sociedad bien planteada es concebida en términos del individuo desanclado de la política tradicional.

Hay que desandar mucho tango, mucha melancolía, mucho narcisismo, desaprender el hábito de la acusación, de la objeción permanente, desactivar la estúpida veneración del impotente pensamiento crítico, esa inteligencia mal entendida, mal ejercida y mal vivida. Hay que deshacer la fascinación por el amor triste, la creencia de que la muerte es prueba de valor o de verdad, la paranoica y también narcisista idea de que hay siempre una maquinación en marcha, alucinadas corporaciones operando para 
destruirnos, como si la vida fuera un cómic y estuviéramos siempre a punto de ser aniquilados por LexLuthor (Rozichner, 2015, p. 7).

El estado contrario a esa utopía individual de desarrollo es la mirada política que tiñe todos los planos de la vida social. En este plano la política se articula con el fanatismo, es decir en la cadena equivalencial del discurso no existe política sin fanatismo, sin violencia y sin la división de la sociedad. La militancia entendida de esta forma se vincula a una disfunción del sujeto más que al compromiso con ideales. Entonces, el militante manifestará en su labor las faltas de otras áreas de su vida pero nunca se constituye en este discurso a la política como aspecto a reivindicar de los hombres.

El militante, el que se enajena con el sentido político, el que cree y dice como recitando un credo que "todo es política" suele tener una historia triste detrás, en su base, que lo hace salir corriendo de su realidad familiar, emotiva y real, para transmutarse en un ser de la historia. Y nadie es un ser de la historia. El militante, ese fanático que rechaza el mundo dado y el reino de lo posible para vivir en su mundo fantaseado y simbólico, padece de algo que lo hace rechazar esa realidad elemental con la que no puede tratar, a la que quiere curar por una vía demasiado indirecta para ser efectiva. Se pone violento, porque su idea del bien suele implicar la necesidad de eliminar y castigar a otros, a los que considera responsables de su malestar (Rozichner, 2015, p. 15).

Pensar el gobierno en el sentido de liberar a los individuos de los pesados lazos de la tradición para dar servicio a los proyectos personales de los habitantes de un país es lo que comienza a articular la propuesta discursiva de Cambiemos con el cambio o la revolución. No estamos en presencia de una identidad que disputa el significante "revolución" en los términos clásicos de la izquierda sino más bien como una reacción con una forma tradicional de la política.

El gobierno del PRO en la capital fue la puesta en marcha de una voluntad de cambio, de un cambio verdadero en la Argentina. Nuestro proyecto político es rebelde y está basado en un deseo 
colectivo. ¿Rebelde el PRO? Sí, exactamente, rebelde con todas las letras, rebelde porque reacciona contra el establishment del retroprogresismo, contra la resignación paranoicocrítica y contra el escepticismo tanguero depresivo y melancólico. [...]

Sí, dije revolución, y no me tembló la mano. El PRO es un emprendimiento con ánimo de cambio, se enfrenta al establishment del pensamiento político convencional, de las ideologías neuróticas y sube la apuesta: logra ayudar a los más necesitados, aquellos que son constantemente aludidos por el discurso popular, pero a los que los políticos que lo encarnan no logran nunca ayudar. ¿Porque no saben o porque no quieren? ¿Es el discurso progresista un paso ineficaz o una fachada para ocultar y justificar la mera delincuencia de la siempre presente corrupción populista? (Rozichner, 2015, p. 17).

El cambio se articula en el discurso con ir contra el establishment. La estructura argumental es la del peronismo, solo que los representantes de las posiciones son otros. Esa elite a la cual hay que combatir no estará compuesta por las grandes corporaciones sino más bien por lo que denominan el retroprogresismo, es decir, por los melancólicos enamorados de la política en sentido tradicional.

\section{El diagnóstico y la historia}

Uno de los aspectos a explorar del discurso de Cambiemos es, sin dudas, la conformación de una tradición política. Las ideologías políticas comparten dos características principales: una representación de la sociedad y un programa político (Eccleshall, 1984). En este aspecto, la acción política buscará vincular estos dos niveles, es decir acercarse al fin deseado a través de una perspectiva coherente.

En este sentido, el reciente gobierno publicó a fines de 2015 un documento llamado El estado del Estado donde realiza un diagnóstico de lo que denominó "la pesada herencia" en la cual el populismo habría dejado al país. Allí interpretaban que el kirchnerismo habría 
...llevado a enojos, a resentimientos, a una búsqueda permanente del enemigo o el responsable, interno o externo, de por qué nos faltan las cosas que nos correspondían. Y hasta nos llevó a aislarnos del mundo, pensando que el mundo nos quería hacer daño ${ }^{17}$.

El diagnóstico se centra en el hallazgo de un Estado en crisis producto de "que no ha parado de crecer y no brinda mejores prestaciones". La crítica apunta a una cuestión global del modelo de desarrollo aplicado poscrisis de 2001. Así, el sobredimensionamiento del Estado está asociado en el discurso a la falta de productividad, a la dificultad para desarrollar el comercio, a un aislamiento internacional que nos habrían alejado de las oportunidades que brindan los nuevos acuerdos de comercio, sobre todo en el área de Asia-Pacífico. El documento identifica que "los controles y atraso cambiario y las trabas, restricciones y burocracia complicaron el comercio internacional y redujeron las exportaciones, las importaciones y el saldo comercial"18.

Esta interpretación comienza a construir la idea de "la pesada herencia" como un modelo populista económico y de gestión del Estado que habría que desarmar para lograr el desarrollo del país. Era, además, una forma estatal anclada en un alineamiento internacional que se debía revisar y modificar sustancialmente.

Esto apunta también a cuestionar los logros que el kirchnerismo se daba, como la mejora en los indicadores sociales y económicos en general. En este aspecto, el discurso se articula con el significante "falso relato" que aglutina y expresa que cada avance de los últimos años era, en realidad, una ficción promovida por el kirchnerismo.

La discusión del "relato" kirchnerista es un elemento central del discurso de Cambiemos; no obstante, existe una dimensión menos explorada que es la de la conformación de una tradición política, la de

\footnotetext{
17 El estado del Estado, documento de Presidencia de la Nación de diciembre de 2015. Recuperado en abril de 2016 de http://www.sigen.gob.ar/pdfs/el_estado_del_estado.pdf 18 El estado del Estado, documento de Presidencia de la Nación de diciembre de 2015.Recuperado en abril de 2016 de http:/ / www.sigen.gob.ar/pdfs/el_estado_del_estado.pdf
} 
un legado que el nuevo gobierno viene a continuar. En ese aspecto, el planteo afirma que, a pesar de los más de treinta años desde que la Argentina recuperó su democracia, los resultados de la misma habrían sido limitados. Esto se articula con la cadena de significación estructurada bajo el "falso relato K" y señalan que "un número inaceptable de argentinos vive en la pobreza, existe gran dificultad para llegar a acuerdos de largo plazo y tenemos un Estado débil frente a desafíos como el del narcotráfico" ${ }^{\prime \prime}$.

¿Cómo se llegó a esta situación? La mirada retrospectiva intenta mostrar que a nuestra democracia le faltó equilibrio entre tres ejes centrales e irreemplazables: institucionalidad, economía dinámica y política social. Cada etapa histórica representa el intento por saldar cada uno de esos ejes. Así, según el relato, Raúl Alfonsín recibió un país herido y fundido de salida de una oscura dictadura por lo que se enfocó en consolidar la institucionalidad democrática.

En la explicación, y siguiendo la línea histórica, Carlos Menem asumió con una democracia aún endeble y con un contexto internacional que también mostraba una gran inestabilidad, con la implosión de la Unión Soviética y el fin de la Guerra Fría. "En ese marco, Menem alineó el país con las tendencias de la época, logró terminar con la inflación e impulsó una apertura económica que buscó consolidar la economía de mercado" 20 .

Tanto Alfonsín como Menem tenían una misión histórica en el relato. Fernando de la Rúa entre tanto, según la línea argumental, llegó a la presidencia justamente con la promesa de mantener la estabilidad económica y agregar la institucionalidad faltante. No logró ninguno de los dos objetivos y poco más de dos años después dejaba la Presidencia en medio de una fulminante crisis política, económica y social.

\footnotetext{
19 Petrella, I. (2016)."El desafío de entrar en la madurez democrática”, en La Nación, jueves 9 de junio de 2016. Cabe destacar que el autor es además secretario de Integración Federal y Cooperación Internacional en el Ministerio de Cultura de la Nación.

20 Petrella, I. (2016). "El desafío de entrar en la madurez democrática", en La Nación, jueves 9 de junio de 2016.
} 
El enemigo político de Cambiemos (el kirchnerismo) se constituye como producto de esa crisis de la etapa neoliberal. A este se le reconoceque logró recomponer el poder de la presidencia, aunque luego exageró al concentrarlo, llevarse por delante la institucionalidad y apropiarse del Estado. El discurso plantea que más desde la retórica que desde la realidad, trató de responder a la gran crisis social que recibió e implementó algunas políticas sociales, pero no habría querido controlar la inflación, ahuyentó las inversiones y le quitó dinamismo al mercado. Cerró su gobierno con casi un tercio de la población en la pobreza y el Estado prácticamente quebrado.

Según esta visión, cada etapa tuvo su rol y su éxito parcial: Alfonsín, consolidar la democracia; Menem, modernizar el mercado y abrirse a las inversiones; y Néstor Kirchner y Cristina Fernández, asegurar un piso social. Como se ve, todas estas expresiones políticas se concentraron en un aspecto y descuidaron los otros.

La etapa que inauguraría Macri debería centrarse en no descuidar ninguno de los anteriores aspectos y combinar institucionalidad, economía dinámica y progreso social. Esta idea de progreso sin disputas se articula con la de la unión de los argentinos tras una democracia desprovista de la dimensión del conflicto.

El gran desafío político, entonces, es romper ese clima irracional. No pasa por una cuestión objetiva de políticas de gobierno. Pasa por convencer a unos y a otros de que no hay razón para desconfiar de todo o para confiar ciegamente en todo. Y en entender que lo más importante es volver a escucharse sin prejuzgar las intenciones del interlocutor, sin suponer de antemano que es malintencionado o artero $^{21}$.

Esta distinción entre dos formas de hacer política se encadenan en un sentido amplio con el resto de América Latina. La política confrontativa es común al populismo de la región y se diferencia de

\footnotetext{
21 Petrella, I. (2016). “Obama, Macri y un país sin matices”, en La Nación, sábado 19 de marzo de 2016.
} 
otros países donde primaría esa racionalidad política que no tendría el populismo. Esto constituye un peligro para la democracia puesto que, desde esta mirada, Venezuela, Argentina, Bolivia y Ecuador son países con gobiernos surgidos de las urnas, pero con un respeto muy variable por los valores republicanos.

Esta concepción del populismo como política confrontativa y escaso respeto a lo que conciben como repúblicas se articula con la idea de formas no democráticas, es decir, en América Latina habría gobiernos surgidos por elecciones, pero no democráticos. Esta distinción permite aglutinar a los democráticos en el ALCA y a los populistas en el Mercosur. Esta operación construye el ideal político del proyecto de Cambiemos que se delinea tras el modelo chileno.

El objetivo de Chile es manifiesto: desarrollar más y mejores lazos comerciales con su vecindario ampliado. Sin embargo, a primera vista, se puede observar que la tarea no será fácil. En particular, parece haber una profunda divergencia entre la concepción de la democracia y la apertura comercial de los miembros de la Alianza del Pacífico y las actitudes de algunos de los integrantes del Mercosur. En la Argentina, estas divergencias quedaron plasmadas en la Cumbre de las Américas de 2005, con la negativa a firmar tratados de libre comercio en el marco del ALCA. En ese entonces, lo que podía haber sido simplemente una decisión económica se convirtió en una bandera política: el proteccionismo era un acto "antiimperialista" en el que nos encontrábamos aliados con países como Cuba y Venezuela ${ }^{22}$.

Elegir entre estos dos polos en Latinoamérica es primordial puesto que implica un posicionamiento global en función de la opción tomada. Ponían el énfasis en lo que denominaban el eje institucional que está vinculado con los valores asociados con la organización política. La pregunta era entonces, ¿qué lugares del mundo se desarrollan y representan valores como los que impulsa Cambiemos? Allí

22 Petrella, I. (2014). “El sistema de alianzas en la región, ¿nuevas perspectivas?”, en La Nación, viernes 1 de agosto de 2014. 
la alianza supone, en esta lectura, el esfuerzo conjunto de los países en desarrollo que la componen para relacionarse con los mercados orientales, altamente prometedores para las economías de América. Ese mundo abierto a las oportunidades sería el reverso del Mercosur cooptado por los gobiernos populistas.

Pero la negativa argentina a una apertura económica inteligente excedió su carácter de decisión comercial y definió tanto los valores institucionales y la inserción estratégica con la región y el mundo, en claro contraste con nuestros socios más próximos y nuestros vecinos. La situación llevó, insólitamente, a que la Argentina, un país históricamente identificado con la defensa de la democracia y de los derechos humanos, quedara asociado con sus mayores detractores a nivel continental y mundial ${ }^{23}$.

Esta negativa a vincularse al lado racional de los países latinoamericanos es lo que habría generado los problemas, el aislamiento y la falta de inversiones en el discurso. La solución a esta cuestión pasa por abandonar la mirada confrontativa y superar la denominada grieta. Ese pasaje es sostenido en una interpretación histórica que culmina con el ejemplo a seguir que sería el abrazo entre Perón y Balbín como cierre de una etapa conflictiva. Era según esta lectura el fin de la enemistad política para plantear ser adversarios y dejar así atrás años de enfrentamiento.

En ese abrazo, como símbolo, se asomó la democracia real: la política intentaba no regirse más por la lógica de amigos y enemigos, que es, en verdad, la lógica de la guerra y de lo que no es política ni democracia. Hoy podemos aprender mucho de ese abrazo. Hace tiempo, el partido gobernante decidió empezar a hablar de política en términos de "nosotros" contra "ellos", marcando una peligrosa antinomia entre quienes supuestamente trabajan por el bien del país y quienes en teoría buscan perjudicar al país. Ya pasaron años de esta retórica en la que el que no coincide con

23 Petrella, I. (2014). "El sistema de alianzas en la región, ¿nuevas perspectivas?”, en La Nación, viernes 1 de agosto de 2014. 
la postura oficial es un enemigo interno, algo que el contexto electoral actual no hizo más que agravar ${ }^{24}$.

El planteo se cierra con la idea de la aparente paradoja producida porque, en el mismo país en el que Balbín y Perón se abrazaron, parecía imposible que Cristina Fernández de Kirchner pudiera abrazar a un Mauricio Macri presidente. Esto era entonces un enorme retroceso para la cultura democrática, entendida esta como el diálogo y los modismos republicanos.

La superación de esta etapa necesitaba un cambio de paradigma, pasar a una mirada optimista que olvide el pasado de desencuentro y construya "la agenda de lo posible desde la empatía y la propuesta superadora”. En este plano los intelectuales tienen una labor que es "aumentar la confianza de la gente en su capacidad de cambio", puesto que, desde el discurso es ir "contra la democracia describir la realidad de tal manera que parezca que no tenemos capacidad para mejorar".

Aquí se da una articulación compleja en términos ideológicos que anuda el pasado conflictivo y populista con la necesidad de olvidar los aprendizajes de la historia para entrar de manera optimista en el futuro. Un futuro en donde los intelectuales no deben denunciar las condiciones de opresión sino más bien ser agentes dinamizadores de la confianza de la gente. El problema es que la mayoría de los intelectuales, tanto los kirchneristas como los antikirchneristas, se habrían formado políticamente durante gobiernos de facto y en el contexto ideológico de la Guerra Fría.

Tal vez en nuestro país también exista la oportunidad para la aparición de una nueva generación de pensadores, probablemente más joven, formada en tiempos de gobiernos democráticos y que no se siente contenida por ninguno de los dos grupos presentados antes. Serán intelectuales con otra visión de la política, del país y del contexto internacional. Estarán más interesados en imaginar

\footnotetext{
24 Petrella, I (2015). “El abrazo democrático de Balbín y Perón”, en La Nación, viernes 4 de septiembre de 2015.
} 
el futuro que en interpretar el pasado y verán al mundo no como una amenaza, sino como una oportunidad para crecer como país y como personas. Su primera reacción ante los problemas y los desacuerdos no será la crítica, sino la empatía, y su segunda reacción será la propuesta superadora. Estos intelectuales tendrán un optimismo contagioso y serán capaces de plantear, concentrarse y privilegiar la agenda de lo posible por sobre la agenda de lo que ya pasó, buscando sacar lo mejor de cada ciudadano en vez de intentar separar quién es bueno de quién es malo ${ }^{25}$.

El gran cambio en la política tiene como pilar, en esta concepción, una renovación de los políticos que serían reemplazados por gente desinteresada del poder en sí mismo. Proponen que para:

La construcción de una Argentina para el siglo XXI no se requiere resucitar o referenciar siempre debates del pasado. Hacerlo sería suponer que el mundo es estático y que los conflictos que dieron lugar a esos debates aún predominan. Eso les permite construir un discurso contra la política tradicional que propondría caminos de desarrollo y esquemas mentales desactualizados. Una política distinta, en cambio, debería enfatizar la búsqueda de soluciones concretas para el presente que potencien, en vez de hipotecar, el largo plazo ${ }^{26}$.

Además, una política no tradicional positiva debe luchar contra la costumbre de la política tradicional anclada en los "liderazgos caudillistas, cuasi mesiánicos, que creen que gobernar es encarnar la voluntad popular" ${ }^{27}$. En definitiva, una política distinta también debería romper con etiquetas y dicotomías como derecha/izquierda, privado/estatal y nacional/extranjero. Es decir, el discurso que se plantea disuelve las tensiones sociales económicas detrás de un significante como la nueva política que anula el conflicto. Esta articulación permite incluir

25 Petrella, I. (2015). “El abrazo democrático de Balbín y Perón”, en La Nación, viernes 4 de septiembre de 2015.

26 Petrella, I. (2013). "Para una nueva política”, en La Nación, jueves 28 de noviembre de 2013.

27 Petrella, I. (2013). “Para una nueva política”, en La Nación, jueves 28 de noviembre de 2013. 
en esa cadena de sentido la oposición al populismo, las políticas intervencionistas, la búsqueda de autonomía estatal a nivel interno como al nivel de los alineamientos internacionales.

\section{Reflexiones finales}

En 2015, el panorama político argentino se modificó sustancialmente al llegar al poder una fuerza política de derecha por la vía electoral. Cambiemos logró articular una serie de demandas dispersas en la superficie política y anudarlas detrás de un significante vacío vinculado al cambio, a las buenas prácticas políticas. La aparente paradoja de esto es que el primer gobierno de derecha democráticamente elegido de la historia argentina llegó al poder con un discurso que logró consolidar un antagonismo en el populismo, identificando esta forma como una manera de hacer política confrontativa, de naturaleza corrupta y a su vez se construyó como la otra herencia de 2001, es decir el ciudadano preocupado, sin experiencia política pero bien intencionado.

Pensar la política en términos relacionales nos permite dar cuenta del complejo reagrupamiento de las identidades en la Argentina post 2001. El artículo da cuenta de cómo se constituyó un relato, una visión coherente del mundo, del presente y el pasado de la Argentina. El objetivo propuesto por el trabajo apuntó a profundizar el análisis en el mapa ideológico construido por la alianza gobernante a partir de revisar textos producidos por sus referentes e intelectuales. El propósito no fue señalar sus "errores" o "falsedades" sino hacer un análisis de cómo esta lectura busca argumentar sobre la necesidad de transformar la sociedad y la política después de 12 años de gobiernos populares de signo contrario.

El título del texto trató de marcar esta tensión entre un discurso que se construye como antipolítico en el plano argumentativo pero que tiene como finalidad transformar las relaciones sociales y de poder, es decir, hacer una profunda transformación política. Con vistas a este objetivo se encontró una recurrente crítica a la militancia, a la acción colectiva organizada, a la historia como legado de las luchas y, en su lugar, se 
destaca una visión que propone avanzar dejando de lado lo que nos ata al pasado asociado a la militancia, a una visión melancólica.

Este es, sin dudas, un aspecto central del discurso. La política, según este relato, debería ser una búsqueda de consensos desanclados de las disputas materiales, cuestiones que la política como es entendida por esta ideología superaría. Podemos pensar también, luego del recorrido por los textos presentados, que el espacio de centro derecha no niega el conflicto, sino que lo explica por una disputa producida artificialmente por el discurso demagógico populista y no por una lucha en el terreno estructural económico. Por ello su insistencia en superar el supuesto estado de crispación de la sociedad a la cual el populismo la habría llevado.

Esto se vincula con un segundo momento en donde se construye la idea de normalizar la política, que se caracteriza por abandonar fanatismos y abrevar al diálogo. Esta mirada despolitizadora es el punto nodal del discurso que articula con una concepción deshistorizadora puesto que el punto que se señala es el abandono de nuestra historia como punto de construcción política y se impulsa un futuro vacío de conflicto como utopía.

En este plano es central retomar la idea del mito como un habla despolitizada en los términos del intento de naturalizar y borrar los condicionamientos históricos políticos de las relaciones sociales. Si entendemos la política en un sentido profundo, como conjunto de relaciones humanas en su poder de construcción del mundo, el mito de la Argentina pacificada y del diálogo constituye una operación tendiente a invisibilizar el conflicto social.

$\mathrm{Al}$ mismo tiempo, el discurso de la alianza Cambiemos cuestiona la vigencia de las categorías de izquierda y derecha, mientras propone una nueva concepción política que deje atrás las viejas nominaciones y formas de identificar los espacios políticos. El trabajo pretende ser un aporte para pensar la dimensión ideológica del nuevo proceso político argentino y constituye un punto de partida para analizarlos horizontes de los "nuevos" discursos e identidades de centro derecha. 


\section{Referencias}

Aboy Carlés, G. (2001). Las dos fronteras de la democracia argentina. La reformulación de las identidades politicas de Alfonsin a Menem. Rosario: Homo Sapiens.

Aboy Carlés, G. (2005). Populismo y democracia en la Argentina contemporánea. Entre el hegemonismo y la refundación. Estudios Sociales, XV, 1er semestre. 125-150.

Aboy Carlés, G. (2011). Papeles de trabajo. Revista electrónica del Instituto de Altos Estudios Sociales de la Universidad Nacional de General San Martin, 5 , (8). Dossier: Identidades, tradiciones y élites politicas.

Alemán, J. (2016). Horizontes neoliberales en la subjetividad. Madrid: Granma.

Alessandro, M. (2009). Clivajes sociales, estrategias de los actores y sistema de partidos: la competencia política en la Ciudad de Buenos Aires (1995-2005), en Revista SAAP, 3 (4). 581-614.

Amossy, R. (2000). L'argumentation dans le discours. Discours politique, littérature d'idées, fiction. Paris: Nathan.

Barros, S. (2006). Inclusión radical y conflicto en la constitución del pueblo populista, Confines, (2-3), 65-74.

Barthes, R. (1999). El mito hoy. Mitologías, Buenos Aires: Siglo XXI Editores.

Biglieri, P. \& Perelló, G. (2007). En el nombre del pueblo. La emergencia del populismo Kirchnerista. Buenos Aires: UNSAM Editora.

Bobbio, N. (1995). Izquierda y derecha. Razones y significados de una distinción política. Madrid: Taurus.

Casullo, N. (2007). Las cuestiones. Buenos Aires: Fondo de Cultura Económica.

Cavarozzi, M. (2011). El peronismo kirchnerista... el peronismo de siempre. Revista Estudios,(26). 13-25.

Conno, D. (2012). Hacia una democracia biopolítica. Rev. Sociedad \& Equidad, (4).

Eccleshall, R. (1993). Ideologías políticas. Madrid: Tecnos.

Franzé, J. (2016). La negación del populismo como fenómeno político. Publico.es. Disponible en http://blogs.publico.es/dominiopublico/15956/ la-negacion-del-populismo-como-fenomeno-politico/

Grüner, E. (2010). La oscuridad y las luces. Buenos Aires: Edhasa.

Hobsbawm, E. (1994). Historia del siglo XX. Madrid: Crítica.

Howarth, D. (2008). Hegemonía, subjetividad política y democracia radical en Chrtichley S. y Marchrt, O. (Comps.). Laclau. Aproximaciones críticas a su obra. Buenos Aires: Fondo de Cultura Económica. 
Laclau, E. (1985a). Tesis acerca de la Forma Hegemónica de la Política. Hegemonía y alternativas políticas en América Latina, Labastida, J. y Del Campo, M. (Comps.). México: Siglo XXI, pp. 19-44.

Laclau, E. (1985b). Ruptura populista y discurso, anexo a Tesis acerca de la formación hegemónica de la política. Hegemonía y alternativas politicas en América Latina, Labastida, J. y Del Campo, M. (Comps.). México: Siglo XXI.

Laclau, E. (1994). ¿Por qué los significantes vacíos son importantes para la política? Emancipación y diferencia. Buenos Aires: Ariel.

Laclau, E. (1998). Deconstrucción, pragmatismo y hegemonía, en Mouffe C. (Comp.) Deconstrucción y pragmatismo. Buenos Aires: Paidós.

Laclau, E. (2000). Nuevas reflexiones sobre la revolución de nuestro tiempo. Buenos Aires: Nueva Visión.

Laclau, E. (2002). El análisis político del discurso: entre la teoría de la hegemonía y la retórica (entrevista). De Signis (2).

Laclau, E. (2005). La rąón populista. Buenos Aires: Fondo de Cultura Económica.

Laclau, E. \& Mouffe, C. (2004). Hegemonía y estrategia socialista. Hacia una radicalización de la democracia. Buenos Aires: Fondo de Cultura Económica. Lipset, S. \& Stein, R. (1967). Cleavage Structures, Party Systems and Voter Alignments: An Introduction, en Lipset, S. y Stein, R. (Eds.). Party Systems and Voter Alignments: Cross National Perspectives. Nueva York: Free Press.

Mc Gee Deutsch, S. (2005). Las derechas. La extrema derecha en la Argentina, el Brasily Chile. 1890-1939. Buenos Aires: UNQ.

Rozichner, A. (2015). Querido Mauricio. Disponible en http://www.queridomauricio.com/Querido_Mauricio_Febrero2015_AlejandroRozitchner.pdf

Vommaro G. \& Morresi S. (2015). Hagamos equipo: PRO y la construcción de la nueva derecha en Argentina. Buenos Aires: Universidad Nacional de General Sarmiento.

Muñoz, A. (2011). Debates sobre la caracterización del giro a la izquierda en América Latina. Todo aquel fulgor. La politica Argentina después del neoliberalismo. Buenos Aires: Nueva Trilce.

Montero, A. (2011). ¡Y al final un día volvimos! Los usos de la memoria en el discurso kirchnerista (2003-2007). Buenos Aires: Prometeo. 
Novaro, M. (2011). La cultura política y el sentido común bajo el kirchnerismo, en Malamud, A. y De Luca, M. (Coords.). La politica en tiempos de los Kirchner. Buenos Aires: Eudeba.

Ostiguy, P. (1999). Peronism and Anti-Peronism: Class-Cultural Cleavages and Political Identity in Argentina. Tesis de doctorado. Berkeley: University of California, mimeo.

Ostiguy, P. (2005). Les gauches en Amérique Latine: un état des lieux. Revue Internationale de Politique Comparée, 12 (3).

Ostiguy, P. (2013a). Politics, Populism, and Drama: On the Fusion of the Leader and the People, ponencia presentada en la reunión de la Latin American Studies Association (LASA), Washington, D. C., 29 de mayo al 1 de junio.

Ostiguy, P. (2013b). Flaunting the "Low" in Politics: A Cultural-Relational Approach to Populism. Ponencia presentada en el Workshop on the Concept of Populism, Universidad de Sussex, 27 al 28 de junio.

Schmitt, C. (1999). El concepto de lo político. Barcelona: Alianza Editorial.

Schuttenberg, M. \& Fontana, J. (2013). La Nación y la herencia perdida de la revolución, 2008-2011, en Quinteros, G. (Comp.). La conmemoración de la Revolución de Mayo. Prensa gráfica, historia y política, siglos XIX-XXI. La Plata: EDULP.

Schuttenberg, M. (2008). Identidades y subjetividades. Planes y política en barrios del Gran La Plata en Revista Question, (19).

Schuttenberg, M. (2008). Sociedad, trabajo y política. Un análisis desde la teoría social contemporánea sobre el proceso de globalización. Revista del Instituto de relaciones Internacionales, 17 (34), 175-195.

Schuttenberg, M. (2014). La oposición al kirchnerismo. Una aproximación a los posicionamientos y reconfiguraciones de la centro derecha (20032011). Revista Sudamérica, (3), 5-74.

Retamozo, M. \& Schuttenberg, M. (2016). La política, los partidos y las elecciones en Argentina 2015: ¿hacia un cambio en el campo político? Análisis Político, (86), 113-140.

Tato, M. I. (2013). El conservadurismo argentino: ¿una categoría evanescente?, en Bohoslavsky, E. y Echeverría, O. (Comps.). Las derechas en el Cono Sur, siglo XX. Actas del tercer taller de discusión. Buenos Aires: Universidad Nacional de General Sarmiento.

Van Dijk, T. (1999). El análisis crítico del discurso. Anthropos, (186), 185-200. 
Verón, E. \& Sigal, S. (2004). Perón o muerte. Los fundamentos discursivos del fenómeno peronista. Buenos Aires: Eudeba.

Vommaro, G., Morresi S. \& Belloti (2014). Mundo PRO. Buenos Aires: Editorial Planeta.

Vommaro, G. \& Morresi S. (2014). Unidos y diversificados: la construcción del partido PRO en la CABA. Revista SAAP8, (2). 